A problemática do abuso sexual infantil questiona a teoria e a prática psicanalítica a partir de sua alta incidência na população feminina. Propomos uma revisão das contribuições de Freud e Laplanche com relação ao tema. $O$ conceito de realidade é posto à prova em seus entrecruzamentos com a ética do analista. Abuso sexual infantil; trauma; constituição subjetiva

THE PROBLEM OF INFANTLE SEXUAL ABUSE IN PSYCHOANALYSIS: WOMEN'S SILENCE

The problem of infantile sexual abuse, through its bigh incidence on the feminine population, interrogate the psychoanalytic theory as well as its practice. A revision of Freud and J. Laplanche's contributions to this topic is set forth. The concept of reality is tested in its interlinking relation with the analysts etbics.

Infantile sexual abuse; trauma; subjective constitution

\section{A PROBLEMÁTICA}

DO ABUSO SEXUAL INFANTIL EM PSICANÁLISE: O SILÊNCIO DAS MULHERES

\author{
Bettina Calvi
}

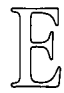

Sste artigo é inaugurado com uma pergunta: sedução precoce infantil ou abuso sexual infantil em psicanálise? Pergunta que se situa em um aspecto importante da problemática escolhida. Há algum tempo, ao escutar pacientes adultas reconstruir cenas nas quais foram vítimas de abuso infantil, surpreende-me a freqüência com que tais situações aparecem na história das mulheres.

Freud em 1896 já se perguntava sobre isso. Esta questão sofreu várias vicissitudes que remetem ao avanço da teoria; e atravessa a psicanálise desde então. É preocupante que esta pergunta não se mantenha como tal para os analistas. Parece que muitos deles e delas tomaram como premissa o "não acreditar em suas neuróticas". Apesar disso, torna-se imprescindivel perguntar-nos como se inscrevem estes fatos na constituição da subjetividade feminina.

A hipótese proposta neste trabalho seria que a experiência de uma sedução real da criança por parte de

Psicanalista, professora da Universidad Nacional de Rosario, Argentina, membro da Fundacion Estudios Clinicos en Psicoanálisis - Arg.

Tradução: Daniela Teperman 
um adulto lesa traumaticamente o psiquismo em constituição, provocando efeitos que, a partir do trabalho analítico, podem ser direcionados a fim de diminuir o sofrimento concomitante. Os efeitos acima mencionados tomarão diferentes formas, entrelaçando-se na história de quem os padece e em todos aqueles aspectos que dizem respeito a sua constituição subjetiva. De nenhuma maneira pode ser abolida a singularidade que constitui a pedra fundamental da clínica psicanalítica.

O conceito de trauma refere-se a um acontecimento da vida do sujeito caracterizado por sua intensidade, pela incapacidade do sujeito de responder a ele adequadamente e o transtorno e os efeitos patogênicos duradouros que provoca na organização psíquica. Em termos econômicos, o trauma caracteriza-se por um afluxo excessivo de excitações, em relação à tolerância do sujeito e a sua capacidade de controlar e elaborar psiquicamente tais excitações.

É provável que este texto conspire contra si mesmo ao invadir uma problemática que diz respeito ao próprio corpo da psicanálise. Grandes teóricos levantaram diferentes bandeiras ao redor desta problemática. Como permitir-me sulcar suas bordas? Talvez porque o desejo do analista não seja cauteloso ao pensar e construir alguma borda quando se trata do sofrimento de seus pacientes.

Quatro mulheres, que até então não pareciam se unir, ligamse rapidamente. Todas elas reconstruíram, reculperaram (o lapso fala da culpa imensa que todas elas suportaram e com a qual reconstruíram as experiências em diferentes momentos de sua análise) episódios infantis nos quais a sedução da menina por um adulto deixou suas marcas.

Ao escrever, descobrimos que a maravilha do texto é, justamente, a disseminação daquela que é vítima em seu próprio corpo; assim faz-se presente. Derrida (1980) propõe que a disseminação é algo que deixou de pertencer ao regime de significado, excedendo não apenas a multiplicidade de significados, mas também o próprio significado. Ele procura ler o significado da disseminação no texto, na escrita; uma vez que ela não pode ser dominada pelo campo semântico nem tampouco pelo temático.

Talvez por esse motivo, neste texto embaralham-se a teoria, a clínica e a escrita, numa confusão que não deixa de preocupar a autora.

Para situar historicamente a problemática dentro da psicanálise: em 1896, em "La herencia y la etiología de las neurosis", Freud propõe como causa específica da histeria "uma experiência sexual passiva antes da puberdade" (p.142). Em setembro de 1897, escreve na Carta 69: "Já não acredito mais na minha neurótica" (p.301).

Em outubro do mesmo ano, fala de eventos universais da infância referindo-se a Édipo e a Hamlet, e situa a base da neurose na fantasia inconsciente. Em 1916, na Conferência 23, Freud cita como um dos acontecimentos presentes na vida dos neuróticos "a sedução por uma pessoa adulta dizendo que seria um erro supor 
que nunca the corresponde uma realidade material; mais ainda, que muitas vezes esta está comprovada" (p.332). Afirma que, com a fantasia de sedução quando esta não ocorreu de fato, a criança encobre o período auto-erótico de seu trabalho sexual. Os casos que não pertenciam à fantasia teriam ocorrido em épocas mais tardias, mas eram atribuídos a uma época anterior. Afirma que o resultado é o mesmo em ambos os casos, e geralmente são estabelecidas relações de complementaridade entre realidade e fantasia.

Em 1923, em "Dos artículos de enciclopedia: psicoanálisis y teoría de la libido", Freud avalia que "foi um erro superestimar a sedução como fonte das manifestações sexuais infantis e gérmen da formação de sintomas neuróticos; erro que é superado ao conhecer a importância da atividade fantasística na vida anímica; a qual considera, para a neurose, mais decisiva que a realidade exterior" (p.128).

Em 1925, em seu texto "Presentación autobiográfica", Freud volta a mencionar como erro sua crença na reprodução, por parte de seus pacientes, de cenas de sedução sexual por um adulto. Em 1931, em seu artigo sobre a sexualidade feminina, afirma que "o influxo que o cuidado do corpo exerce sobre o despertar sexual é testemunhado pela freqüente fantasia na qual a mãe ou a ama é a sedutora". Também afirma que "a sedução real é muito freqüente por parte de outras crianças ou de pessoas encarregadas de cuidar da criança". Dirá que "toda vez que ocorre uma sedução, freqüentemente deixa como seqüela vastas e duradouras conseqüências" (p.38).

Notemos que, no último fragmento citado, Freud diferencia o influxo que os primeiros cuidados do corpo exercem sobre o despertar sexual, da sedução real, da qual pode encarregar-se um adulto.
Não há dúvidas de que essas oscilações de Freud têm a ver com movimentos internos da teoria que estava construindo. Mas como lemos hoje - os analistas e as analistas - esta problemática? Pode-se intervir do mesmo modo no caso em que a sedução ocorreu efetivamente sobre a criança e naquele em que se trata de uma fantasia?

Freud abandona a teoria da sedução quando descobre que as cenas de sedução são algumas vezes o produto de reconstruções fantasmáticas, descoberta que ocorre paralelamente ao desvelamento progressivo da sexualidade infantil. De qualquer forma, Freud não deixou de acreditar na existência, freqüência e valor patogênico das cenas de sedução efetivamente vivenciadas pelas crianças. Mas também afirma que a sedução ocorre freqüentemente em um período tardio, sendo uma outra criança o sedutor. Mais adiante, a sedução é atribuída a um fantasma retroativo, a um período precoce e imputada a um personagem parental.

Laplanche, em seu artigo "De la teoría de la seducción restringida a la teoría de la seducción generalizada", trata de como se conjugam dois elementos: a realidade efetiva de uma sedução e a teoria da sedução.

Designa como sedução infantil os fatos de sedução abordados por Freud; são cenas que podem ser reconstruídas na análise. Retomando o conceito de trauma, trata de designar um caráter essencial que possibilitaria a passagem da teoria da sedução, tal como foi proposta até 1897 , com as reinscrições possíveis a partir das reformulações produzidas depois de 1920. Se o adulto é o partenaire responsável pela sedução, o caráter essencial próprio da cena será dado pela essência da própria sedução: a passividade da criança diante do adulto. A passividade essencial da criança, confrontada à sexualidade adulta, deve 
ser reinscrita em função do encadeamento e da sucessão de cenas sexuais. A psicanálise guarda como aquisição o aspecto temporal desta teoria: apréscoup o traumatismo em dois tempos. Postula que nada se inscreve no inconsciente humano senão na relação de ao menos dois acontecimentos, separados no tempo por um momento de mutação que permite ao sujeito reagir de outro modo à primeira experiência. Constitui assim um autotraumatismo capaz de inaugurar a possibilidade de sair da oposição entre fatores exógenos e endógenos; a partir disso, tudo é exógeno e tudo é endógeno.

Afirmação forte, em relação à qual cabe a pergunta: trata-se da mesma coisa?

Às quatro pacientes que inspiraram este artigo, acrescenta-se, de repente, uma criança. Trata-se de uma pequena paciente de 4 anos, atendida já há bastante tempo, na ocasião em que se comprovou que foi vítima de abuso por parte de seu padrasto. A teoria que ela construiu em torno do que ocorreu era a seguinte: "Podem fazer qualquer coisa com as mulheres, porque não podem se defender, porque não têm pipi". A analista intervém marcando que as mulheres também podem se defender, ainda que não tenham pipi; e além disso, se for necessário, podem pedir ajuda. Quando este material foi levado para supervisão, surgiu a idéia de que essa intervenção obturou a produção da paciente, que poderia ter expressado do que sentia que as mulheres tinham de se defender, e continuar assim com a cadeia associativa. A primeira pergunta seria: a analista pode perguntar, a uma menina abusada sexualmente durante um ano, do que as mulheres têm de se defender, quando até mesmo sua própria mãe silenciou o fato? Neste breve fragmento clínico há um entrecruzamento de várias questôes: as represen- tações que a menina apresenta sobre as mulheres e seu destino, as representações da analista diante do abuso infantil, a ética da analista, o discurso da instituição psicanalítica representada pela supervisão e as teorias sexuais infantis questionadas pela intrusão de um adulto perverso e seus efeitos sobre o psiquismo infantil.

Devido à gravidade da questão para o psiquismo em constituição, a intervençào que o analista ou a analista realize será de importância crucial. Agora, o analista ou a analista estará por sua vez atravessada por sua própria subjetividade enlaçada com a teoria psicanalítica, que apresenta a esse respeito os movimentos - que mostrei no percurso histórico - pelas representações que a partir do social o impregnam ou a impregnam e pelas representações que a instituição analítica sustenta a respeito. Conforme observamos no fragmento, parece que, para a instituição psicanalítica, representada pela supervisão, o abuso passa a segundo plano, e essa menina poderia ser escutada como outra que não tivesse passado por esta experiência.

Experiência que a partir deste artigo é designada como traumática; e que fica inscrita na forma de um pictograma.

Para a analista, o impacto que a violência sobre a menina - cujo corpo é usado para a satisfação sexual de um adulto - provoca sobre sua subjetividade de mulher, mobilizará suas representações sobre as mulheres, sobre a sexualidade infantil, e isso marcará suas intervenções, que deverão ser discriminadas daquelas que, a partir de outros discursos, se dirigirão para a menina, numa avalanche de "boas intenções" que podem ser traduzidas em tentativas de apagar o ocorrido para não provocar maior angústia.

Agora, estas quatro mulheres e a menina encontram-se? Onde? Em que 
ponto do texto? Ou devo perguntar em que lugar do texto encontram-se estas seis mulheres? Pois trata-se de quatro pacientes adultas, uma paciente criança e a analista. Se encontram-se na sexualidade feminina, todas elas ficam envolvidas. Corpo das mulheres. Corpo que se inscreve no discurso psicanalítico.

Bleichmar (1994) propõe (desde um lugar polêmico para a teoria, já que questiona pontos nodais do corpus teórico psicanalítico a partir das teorias do gênero) que "o campo do olhar olhar ser olhada - é o terreno mais freqüente de experiência da sedução infantil pai(adulto)-menina. Será no corpo da menina-futura mulher que pousará o olhar sedutor do adulto homem. Olhar sexual que inaugura um espaço intersubjetivo silencioso e secreto, na medida em que é apenas isso: olhar. Isso implanta na subjetividade da menina uma codificaçâo de seu corpo que a acompanhará daqui em diante: seu caráter provocador. A menina, como toda mulher, como o mito de Eva o expressa e o multiplica, "é provocadora e culpada por possuir um corpo que atrai o olhar. É este caráter provocador em que a provocação consiste não na intencionalidade do ato, mas na posse de um atributo, o que caracteriza a especificidade da condição traumática da construção do significado sexual na menina; pois, ainda que se trate de uma experiência inicialmente passiva, a mente infantil confronta-se com ela como um ato (de caráter ativo). Desta maneira o adulto homem contribui para a implantação intrusiva na subjetividade feminina de um corpo estranho interno, de um significado sexual do corpo feminino que tem como efeito subjetivo um amálgama responsável por manifestaçōes habituais nas meninas, tais como Freud o descreve no caso Emma: 'A má consciência oprimente'. Trata-se então da posse de um corpo provocador".
Cinco anos depois, a paciente menina, já púbere, volta a procurar-me apresentando uma sintomatologia variada, em que se destacam uma empobrecida imagem de si mesma, um corpo que sente como desagradável e que deve ser escondido, uma inibição cognitiva, o sentimento generalizado de que sua palavra não tem valor, e um fundo depressivo importante. Desta vez a analista, menos temerosa, está disposta a reconstruir, a suportar o peso da recordação do abuso infantil que ocorreu de fato, e seus efeitos, autorizandose a trabalhá-lo sem sentir que está traindo os preceitos da teoria. Assim é que a menina pode recuperar, trabalhosamente, sua história, que tinha sucumbido junto com a recordação dos episódios vivenciados. As dificuldades escolares começam a diminuir, e começam a ocorrer, ainda que lentamente, vínculos com seus pares, que eram quase inexistentes.

Este texto, sulcado por perguntas, associações, construções, apresenta-se como um enigma, que também provoca. Assim como enigmáticos e provocativos são os significantes postos em jogo: sexualidade, corpo, mulheres, meninas, ética, psicanálise. Mas trata-se de provocar a palavra, com a qual pode-se concordar ou não, aceitar, recusar, divergir, questão absolutamente diferente da imposição de um ato violento diante do qual a subjetividade fica abolida, e não há possibilidade de recusa; ainda mais quando quem o exerce é um adulto - representante do poder e portador de normas que dizem respeito à cultura - e a vítima é uma menina.

Como fica inscrita a sedução sexual infantil por um adulto na construção de um passado? Piera Aulagnier (1991) afirma que na adolescência deve-se realizar um trabalho nodal: o acesso a uma ordem temporal, que preserva o sujeito desta confusão de tempo 
própria da psicose. Isto só é possível se o eu, no curso mesmo de sua infância, constituiu esse fundo de memória no qual são preservados certos elementos, momentos, marcos de sua própria história libidinal. Mas este fundo de memória deverá depender desse capital fantasmático do qual o eu deve dispor livremente a fim de que seu acervo de recordações fique dotado desse poder emocional sem o qual todo novo encontro será desprovido de todo poder de gozo e sofrimento. Logo, como funcionará isso quando o desmentido tiver perfurado com lentidão e persistência o eu em constituição? (Aulagnier, 1991).

Nos quatro casos de pacientes adultas, ao conseguirmos reconstruir e trabalhar esses episódios silenciados por tanto tempo, produziram-se importantes movimentos em seu posicionamento subjetivo; movimentos concernentes ao sentimento de si e às relações objetais. Piera Aulagnier (1991) propõe um conceito ao qual dá importância fundamental na compreensão da metapsicologia psicanalítica, o conceito de modificação. A reação do aparelho psíquico ao que surge, muda, desaparece da cena da realidade, e sobre sua própria cena somática, é o organizador dos mecanismos aos quais este mesmo aparelho recorre para, dependendo do caso, aceitar, negociar, desmentir este movimento que contribui com uma parte de imprevisto e desconhecido.

O valor desse conceito é confirmado pela análise da relação de interdependência presente entre o modificável e o nào modificável no registro relacional e no registro identificatório.

Essas idéias permitem-nos pensar nas modificações que são produzidas na subjetividade em seguida da análise destas vivências. Como se inscrevem nessas meninas o silêncio no qual tiveram que guardar esses fatos e a tergi- versação da função do adulto que, longe de sustentar e cuidar, torna-se persecutório e perigoso?

Devemos levar em conta o conceito de desmentido ou denegação, como mecanismo de defesa consistente no qual o sujeito recusa-se a reconhecer a realidade de uma percepção traumatizante. Mas, se este mecanismo é muito utilizado, o psiquismo é danificado. No caso do abuso sexual, a vítima, aqueles que presenciam o abuso e aqueles que escutam e não acreditam naquele que o denuncia recorrem ao desmentido. Diferentemente do que ocorre na repressão, no desmentido, a percepção dada por inexistente provém da realidade externa: algo que existe não existe. Logo, o próprio eu fica danificado, uma vez que é atacada sua capacidade de reconhecer uma percepção, de aceitar algo como existente, de discriminar como própria uma sensação corporal.

Todo acontecimento real implica uma tradução e inscrição psíquica. $O$ desejo dos pais articula-se inconscientemente com os valores dominantes, modelados no supereu; a família é mediadora dos valores dominantes e os reproduz através do inconsciente de seus integrantes.

Muitos formularão a pergunta fundamental: isso ocorreu de fato? A realidade psíquica dará conta de como se inscreveram os fatos na singularidade da fantasmática subjetiva. Isso não é a mesma coisa que pôr em dúvida que estes fatos tenham efetivamente ocorrido. Aqui está o dilema; pedra fundamental da psicanálise, etiologia das neuroses, ética do analista e outras questões medulares da psicanálise entram em jogo.

Nos cinco casos mencionados, a reconstrução dolorosa, infestada de medo, recomposta através da recordação de sensações, mostra o substrato real de uma versão que não foi construída 
conscientemente. Substrato que elas se empenharam em esquecer durante muito tempo. Silêncio das mulheres; não necessariamente silêncio das histéricas.

Percorrendo alguns conceitos para tratar de pensar nelas: Horstein (1998), em seu artigo "Hacia una clínica del narcisismo", propõe que, ao considerar o narcisismo como uma etapa na história libidinal da constituição do eu e as relações com os objetos, suas perturbações assumem duas modalidades: no narcisismo expansivo, uma série contínua de relações de objeto cumprem a função narcísica de compensar a fragilidade do sentimento de si; no outro caso, a defesa é contra o perigo de fusão-confusão. Neste narcisismo retraído predomina a distância com o objeto e a negação de toda dependência. Afirma que a oposição entre estrutura e acontecimento não pode ser absoluta, uma vez que uma flutuação menor desempenha um papel essencial na constituição da estrutura e em sua transformação. A repressão originária, a passagem do eu do prazer ao eu da realidade, o sepultamento do Complexo de Édipo, a metamorfose da puberdade $\mathrm{e}$ todo luto que produz uma recomposição, não serão processos de auto-organização?

Em seguida, entendemos que se pergunte se poderíamos considerar a experiência atual um processo de autoorganização. Agora, proponho que o fato de encontrar um outro, neste caso, a analista, que cria na palavra do sujeito sem desconsiderá-la, inscrevendo deste modo que não ratifica um ato proibido pelas leis da cultura, tem a força de um ato analítico. Ao ocorrer a reconstrução no espaço transicional da análise, permite-se uma nova volta à subjetividade; novo posicionamento, reordenamento, que se embaralha com as produções da fantasia inconsciente, sem ser a mesma coisa. Uma dessas mulheres relata que sua filha púbere pôde lhe contar como se defendeu de um homem, que, enquanto the vendia guloseimas, quis apalpá-la. Uma menina que pode se defender, que não fica situada como vítima da violência de um adulto perverso. Uma menina que pode denunciar esta situação a sua mãe. Uma mãe que pode escutar, e acreditar em sua filha. Um fato que não é silenciado, uma transgressão que não é ratificada a partir do mundo dos adultos. Uma história que não se repete.

Outra dessas mulheres diz que já não estabelece relações com parceiros que a machucam de alguma maneira; pergunta-se como pôde chegar a pôr em perigo até mesmo sua vida nessas relações; ocupando um lugar de submissão diante de um outro que anulava sua subjetividade. Ao terminar sua análise, deixa um bilhete para a analista: "Obrigada, por ajudar-me a reordenar, com as mesmas partes, outra figura". Uma mulher que, ao reconstruir seu passado em seus momentos mais dolorosos, recupera sua capacidade de produzir, até mesmo de escrever, apesar de ter sido diagnosticada como disléxica desde a infância. Seu enunciado recorda a proposta de Ricardo Rodulfo: pensar a reconstrução do mito familiar na forma de um collage no qual não existe uma forma única de montagem, mas uma multiplicidade de composições singulares (Rodulfo \& Rodulfo, 1986).

Poderíamos pensar que a reconstrução, a recordação e a elaboração desses fatos na análise provocaram recomposições que permitiram a essas mulheres modificarem seu posicionamento subjetivo ao deter a compulsão à repetição à qual estavam submetidas. Os efeitos sobre o psiquismo em constituição dependeram em cada caso do trabalho subjetivo em que cada uma se encontrava, ao ocorrer o fato. Cabe 
destacar que se tratava de meninas, e, portanto, falamos de um psiquismo em constituição; constituição que atravessa momentos diferentes com trabalhos que são próprios a cada um deles. Acredito que em todos os casos o abuso infantil revestiu-se de caráter traumático, que desencadeou seus efeitos pela compulsão à repetição; entendendo esta como $o$ processo de origem inconsciente em virtude do qual o sujeito situa-se ativamente em situações penosas, repetindo assim experiências antigas, sem recordar a experiência original, mas, pelo contrário, com a impressão muito viva de que se trata de algo plenamente motivado pelo momento atual.

Mais que concordar ou não com o que as hipóteses aqui propostas provocam, é importante destacar que, como analista, o trabalho sobre esta problemática reinscreveu para mim uma velha aposta: a de aliviar o sofrimento do paciente por meio da psicanálise, que acredito ser a teoria mais completa para dar conta do psiquismo humano.

P. S.: Meu mais profundo agradecimento a meus pacientes que confiaram em mim para internar-se na mágica e difícil aventura de escutar e recuperar suas palavras e sua história.

\section{REFERÊNCIAS BIBLIOGRÁFICAS}

Aulagnier, P. (1991). Construirse un pasado. Revista de Psicoanálisis APDEBA. Vol. XIII, $n^{\circ} 3$.

Bleichmar, D. E. (1994). La niña y la constitución de la sexualidad femenina. Revista Zona Erógena, $\mathrm{n}^{\circ} 20$.

Derrida, J. (1980). La diseminación. Barcelona: Espiral.

Freud, S. (1896). La herencia y la etiología de la neurosis (vol 3, p.139-156). Obras completas. Buenos Aires: Amorrortu, 1976 a.

(1897). Carta 69. In Fragmentos de la correspondencia con Fliess. Obras completas (vol 1, p. 301-302). Buenos Aires: Amorrortu, $1976 \mathrm{~b}$.

(1916). Conferencia 23. In Conferencias de introducción al psicoanálisis (vol 15, p. 326-343). Obras completas. Buenos Aires: Amorrortu, 1976 c

(1925). Dos artículos de enciclopedia: psicoanálisis y teoría de la libido. Obras completas (vol 18, p.227-230). Buenos Aires: Amorrortu, $1976 \mathrm{~d}$.

(1925). Presentación autobiográfica. Obras completas (vol 20, p.1-70). Buenos Aires: Amorrortu, 1976e.

(1931). Sobre la sexualidad femenina. Obras completas (vol 21. p. 223-244). Buenos Aires: Amorrortu, $1976 f$.

Horstein, L. (1998). Hacia una clínica del narcisismo. Artigo inédito.

Laplanche, J. (1988). De la teoría de la seducción restringida a la seducción generalizada. Revista Trabajo del Psicoanálisis. Vol. $3, n^{\circ} 9$.

Rodulfo, R. \& Rodulfo, M. (1986) Clinica psicoanalítica con niños $y$ adolescentes. Buenos Aires: Ediciones Lugar. 